\title{
Prognostic Nomogram That Predicts Overall Survival of Patients with Distal Cholangiocarcinoma After Pancreatoduodenectomy
}

This article was published in the following Dove Press journal: Cancer Management and Research

\author{
Qiao Chen (1D ${ }^{1, *}$ \\ Jiayi $\operatorname{Li}{ }^{1,2, *}$ \\ Bao Jin' \\ Xiangan Wu' \\ Yue Shi ${ }^{1}$ \\ Haifeng Xu' \\ Yongchang Zheng' \\ Yingyi Wang (iD ${ }^{3}$ \\ Shunda Du' \\ Xin Lu' \\ Xinting Sang iD ${ }^{\prime}$ \\ Yilei Mao id \\ 'Department of Liver Surgery, Peking \\ Union Medical College Hospital, Chinese \\ Academy of Medical Sciences and Peking \\ Union Medical College, Beijing, People's \\ Republic of China; ${ }^{2}$ Department of \\ Nuclear Medicine, Peking Union Medical \\ College Hospital, Chinese Academy of \\ Medical Sciences and Peking Union \\ Medical College, Beijing, People's \\ Republic of China; ${ }^{3}$ Department of \\ Oncology, Peking Union Medical College \\ Hospital, Chinese Academy of Medical \\ Sciences and Peking Union Medical \\ College, Beijing, People's Republic of \\ China
}

*These authors contributed equally to this work.
Purpose: We aimed to develop a nomogram for predicting the prognosis of patients with distal cholangiocarcinoma (DCC) and to compare its performance with that of the American Joint Committee on Cancer (AJCC) TNM system.

Patients and Methods: To develop a nomogram, we collected the clinical data of 147 patients diagnosed with DCC who underwent pancreatoduodenectomy. Predictive accuracy and discriminative ability were determined using a concordance index and a calibration curve. Predictive performance was compared with that of a current staging systems for DCC. Results: Multivariate analysis revealed that jaundice, alcohol consumption, high fibrinogen, poorly differentiated tumor cells, positive lymph nodes, and positive margins were significantly associated with overall survival. These variables were incorporated into the nomogram. The concordance index of the nomogram for predicting overall survival was 0.737 $(\mathrm{P}<0.001)$, which is significantly higher than the concordance index values (concordance index $=0.586$ ) acquired using the AJCC TNM system (eighth edition). The calibration curve agreed well with predicted prediction and observed overall survival.

Conclusion: We developed a nomogram for predicting the prognoses of patients with distal cholangiocarcinoma, which had superior practical clinical value compared with that of the AJCC TNM system.

Keywords: distal cholangiocarcinoma, prognostic factors, nomograms, pancreatoduodenectomy, survival analysis

\section{Introduction}

The incidence of cholangiocarcinoma has continued to rise during the past 40 years. ${ }^{1,2}$ China has a high incidence of cholangiocarcinoma, which is 3 times higher than that of Europe or the United States. ${ }^{3}$ Cholangiocarcinoma originates in the bile duct epithelium and comprises intrahepatic cholangiocarcinoma (ICC), perihilar cholangiocarcinoma (PCC), and distal cholangiocarcinoma (DCC). ${ }^{4}$ The average overall survival of patients with untreated cholangiocarcinoma after clinical symptoms appear is less than 6 months. ${ }^{5}$ The diagnostic gold standard is postoperative histopathology. ${ }^{6}$ Early symptoms are not diagnostic, and cholangiocarcinoma is therefore often difficult to diagnose during its early stages. ${ }^{7}$ Overall survival rates of patients differ greatly among clinical studies. Therefore, the factors that determine the prognosis of patients with cholangiocarcinoma is of obvious concern.

Previous studies collected relevant patient information, including preoperative baseline information, preoperative complaints, preoperative test indicators, and
Department of Liver Surgery, Peking

Union Medical College Hospital, Chinese

Academy of Medical Sciences and Peking

Union Medical College, Beijing, People's

Republic of China

Email dushd@pumch.cn
Cancer Management and Research 2020:12 10303-10310

10303 
postoperative pathology. ${ }^{8}$ These factors were then analyzed and used to evaluate prognosis. ${ }^{9}$ The results typically vary, and the possible risk factors are inconsistent. ${ }^{6}$ These findings strongly indicate that determining the prognosis of patients with cholangiocarcinoma requires multifactorial analyses.

Nomograms serve as an alternative method for cancer prognosis $^{10,11}$ and include several for evaluating ICC and PCC. ${ }^{12,13}$ However, we are unaware of attempts to develop a nomogram for patients with DCC in China. ${ }^{14}$ With the development of surgical techniques and postoperative chemotherapy, the survival rate of patients with cholangiocarcinoma is much higher than that of patients 10 years ago. Most published research includes data accumulated over the past 10-20 years to provide a sufficient sample size, which may bias the results. Thus, here we enrolled 147 patients with DCC who were treated at Peking Union Medical College Hospital (PUMCH) between 2012 and 2017. We collected data for selected variables to identify significant prognostic indicators for the purpose of developing a suitable nomogram. Moreover, we compared the performance of the nomogram with that of the American Joint Committee on Cancer (AJCC) TNM system, which is the standard system used to predict the prognosis of patients with DCC.

\section{Patients and Methods}

\section{Patients}

We analyzed the records of patients diagnosed with primary DCC who subsequently underwent pancreatoduodenectomy at PUMCH from January 2012 to December 2017. All patients included in our study underwent standard pancreatoduodenectomy and standard postoperative chemotherapy. Oncologists followed the AJCC guidelines to determine lymph node dissection strategies. Few patients received neoadjuvant chemotherapy, and we therefore excluded those administered neoadjuvant chemotherapy and those who underwent nonsurgical treatment (transcatheter arterial chemoembolization or radiofrequency ablation). We excluded those with carcinomas with mixed histopathologies and distal metastasis as well as those who died of operative or postoperative complications (such as pancreatic fistula, biliary fistula, bleeding, and infection). We included 147 patients in the present study who granted their written informed consent. The Ethics Committee of Peking Union Medical College Hospital approved the study. This study was conducted in accordance with the Declaration of Helsinki.
Table I Demographic and Patient Characteristic in the Entire Cohort $\left(n^{\dagger}=147\right)$

\begin{tabular}{|c|c|c|}
\hline Variables & & Patient Characteristics \\
\hline Age/y, mean $\pm \mathrm{SD}^{\ddagger}$ & & $61.3 \pm 9.1$ \\
\hline \multirow[t]{2}{*}{ Sex n (\%) } & Female & 52 (35.4\%) \\
\hline & Male & 95 (64.6\%) \\
\hline \multirow[t]{2}{*}{ Jaundice n (\%) } & Yes & 117 (79.6\%) \\
\hline & No & $30(20.4 \%)$ \\
\hline \multirow[t]{2}{*}{ Fever n (\%) } & No & I 32 (89.8\%) \\
\hline & Yes & $15(10.2 \%)$ \\
\hline \multirow[t]{2}{*}{ Drink n (\%) } & No & $114(77.6 \%)$ \\
\hline & Yes & $33(22.4 \%)$ \\
\hline \multirow[t]{2}{*}{ Diabetes mellitus n (\%) } & No & 124 (84.4\%) \\
\hline & Yes & $23(15.6 \%)$ \\
\hline $\mathrm{Alb}^{\S}$, mean $\pm \mathrm{SD}$ & & $30.8 \pm 4.0$ \\
\hline Fbg", mean $\pm S D$ & & $4.6 \pm 1.3$ \\
\hline \multirow[t]{2}{*}{ CAl9-9tt n (\%) } & Normal & $18(13.1 \%)$ \\
\hline & Elevated & 119 (86.9\%) \\
\hline \multirow[t]{2}{*}{ Differentiation $\mathrm{n}(\%)$} & Poor & 49 (34.8\%) \\
\hline & Well & 92 (65.2\%) \\
\hline \multirow[t]{2}{*}{ Positive margin n (\%) } & Negative & $106(73.6 \%)$ \\
\hline & Positive & $38(26.4 \%)$ \\
\hline \multirow[t]{2}{*}{ Lymph node n (\%) } & Negative & 95 (66.9\%) \\
\hline & Positive & 47 (33.1\%) \\
\hline \multirow[t]{2}{*}{ Nerve invasion n (\%) } & Negative & $89(60.5 \%)$ \\
\hline & Positive & $58(39.5 \%)$ \\
\hline \multirow[t]{2}{*}{ Angioma embolus $\mathrm{n}(\%)$} & Negative & $123(84.8 \%)$ \\
\hline & Positive & $22(15.2 \%)$ \\
\hline \multirow[t]{3}{*}{ TNM ${ }^{\ddagger}$ staging $n(\%)$} & I & $56(43.8 \%)$ \\
\hline & 2 & 25 (19.5\%) \\
\hline & 3 & 47 (36.7\%) \\
\hline
\end{tabular}

Notes: ${ }^{\dagger} \mathrm{n}$, numbers; ${ }^{\ddagger} \mathrm{SD}$, standard deviation; ${ }^{\S} \mathrm{Alb}$, albumin; ${ }^{\top} \mathrm{Fbg}$, fibrinogen; ${ }^{+\dagger}$ CA199, carbohydrate antigen 19-9; ${ }^{\ddagger}$ TNM, tumor node metastasis.

\section{Measurements}

The preoperative demographics and clinical information collected from medical records and clinical follow-up visits were as follows: age at diagnosis; sex; alcohol consumption (defined as $>4$ "standard drinks"/day for men and 3 "standard drinks"/ day for women [1 standard drink $=14$ grams of alcohol]); preoperative fever; jaundice preceding bile drainage; diabetes mellitus; hypertension; preoperative levels of carbohydrate antigen 19-9 (CA19-9), bilirubin, albumin, and fibrinogen (Fbg); surgical procedure; tumor node metastasis (TNM) stage according to the TNM classification system of the 
AJCC (eighth edition); largest tumor diameter; and histological information including histological type, surgical margins, presence of lymph node metastasis, nerve invasion, and angioma embolus.

\section{Statistical Analyses}

Preliminary univariate analyses were performed to identify potential risk factors, and multivariate analyses were subsequently performed using backward procedures to select a best-fit model. A variable with a $\mathrm{P}$ value less than 0.2 in

Table 2 Univariate Cox Regression Analysis of Clinicopathological Factors Associated with Overall Survival

\begin{tabular}{|c|c|c|c|c|}
\hline \multirow[t]{2}{*}{ Variables } & & \multicolumn{3}{|c|}{ Univariable Analysis } \\
\hline & & $\mathbf{H R}^{\dagger}$ & $95 \% \mathrm{Cl}^{\ddagger}$ & P value ${ }^{\S}$ \\
\hline Age & & 1.00 & $0.97-1.03$ & 0.839 \\
\hline Sex & $\begin{array}{l}\text { Female } \\
\text { Male }\end{array}$ & 1.49 & $0.83-2.69$ & 0.182 \\
\hline Jaundice & $\begin{array}{l}\text { No } \\
\text { Yes }\end{array}$ & 1.59 & $0.82-3.07$ & 0.170 \\
\hline Fever & $\begin{array}{l}\text { No } \\
\text { Yes }\end{array}$ & 0.65 & $0.29-1.44$ & 0.288 \\
\hline Drink & $\begin{array}{l}\text { No } \\
\text { Yes }\end{array}$ & 1.57 & $0.89-2.76$ & 0.118 \\
\hline Diabetes mellitus & $\begin{array}{l}\text { No } \\
\text { Yes }\end{array}$ & 1.46 & $0.77-2.75$ & 0.246 \\
\hline $\mathrm{Alb}^{\pi}$ & & 0.98 & $0.94-1.02$ & 0.346 \\
\hline $\mathrm{Fbg}^{\mathrm{t \dagger}}$ & & 1.28 & $1-1.64$ & 0.048 \\
\hline CAI99 & $\begin{array}{l}\text { Normal } \\
\text { Elevated }\end{array}$ & 0.76 & $0.36-1.63$ & 0.481 \\
\hline Differentiation & $\begin{array}{l}\text { Well } \\
\text { Poor }\end{array}$ & 2.73 & $\mid .62-4.61$ & $<0.001$ \\
\hline T stage & $\begin{array}{l}\text { TI } \\
\text { T2 } \\
\text { T3 }\end{array}$ & $\begin{array}{l}\text { Reference } \\
1.37 \\
1.91\end{array}$ & $\begin{array}{l}0.67-2.8 \\
0.9-4.07\end{array}$ & $\begin{array}{l}0.244 \\
0.390 \\
0.093\end{array}$ \\
\hline Nodes & $\begin{array}{l}\text { Negative } \\
\text { Positive }\end{array}$ & 1.89 & $1.11-3.2$ & 0.018 \\
\hline Margin & $\begin{array}{l}\text { Negative } \\
\text { Positive }\end{array}$ & 2.11 & $1.24-3.58$ & 0.006 \\
\hline Nerve invasion & $\begin{array}{l}\text { No } \\
\text { Yes }\end{array}$ & 0.98 & $0.58-1.66$ & 0.936 \\
\hline Angioma embolus & $\begin{array}{l}\text { No } \\
\text { Yes }\end{array}$ & 1.01 & $0.48-2.14$ & 0.972 \\
\hline
\end{tabular}

Notes: ${ }^{\dagger} \mathrm{HR}$, hazard ratio; ${ }^{\ddagger} 95 \% \mathrm{Cl}, 95 \%$ confidence interval; ${ }^{\S} \mathrm{P}$ value $<0.05$, significant; ${ }^{\top}$ Alb, albumin; ${ }^{\dagger \dagger} \mathrm{Fbg}$, fibrinogen; ${ }^{\ddagger \ddagger} \mathrm{CA} 199$, carbohydrate antigen 19-9. a univariate analysis. A statistical significance level of 0.2 was used to select variables into the model. A nomogram was constructed based on the results of multivariate analysis.

The performance of the nomogram was measured according to a concordance index ( $\mathrm{C}$-index), and calibration curves employed a bootstrapped sample. The $\mathrm{C}$-index based on the nomogram was compared with that of the AJCC TNM system. Model validation was performed using bootstrap resampling to quantify overfitting of our modeling strategy and to evaluate its predictive significance. Statistical analyses were performed using the package in R version 3.4.1 (http://www.r-project.org/).

\section{Results}

Patients' $(n=147)$ characteristics are listed in Table 1 . The average age was $61.3 \pm 9.1$ years, and 52 women $(35.4 \%)$ and 95 men (64.6\%) were included. By the end of this study, 59 patients died because of distal cholangiocarcinoma, 5 patients were lost to follow-up, and 83 patients were alive. The average follow-up was 21.1 months (Table 1).

Backward stepwise selection identified several variables that were significantly associated with overall survival as follows: jaundice (Hazard Ratio [HR], 1.84; 95\% Confidence Interval (CI), 0.90-3.75; P =0.094), alcohol consumption (HR, 1.63; 95\% CI, 0.88-3.02; P=0.120), high Fbg $(\mathrm{HR}, 1.35 ; 95 \% \mathrm{CI}, 1.01-1.80 ; \mathrm{P}=0.043)$, poorly differentiated tumor cells (low differentiation) (HR, 2.58; 95\% CI,

Table 3 Multivariate Cox Regression Analysis of Clinicopathological Factors Associated with Overall Survival

\begin{tabular}{|c|c|c|c|c|}
\hline \multirow[t]{2}{*}{ Variables } & & \multicolumn{3}{|c|}{ Multivariable Analysis } \\
\hline & & $\mathbf{H R}^{\dagger}$ & $95 \% \mathrm{Cl}^{\ddagger}$ & P value $\S$ \\
\hline Jaundice & $\begin{array}{l}\text { No } \\
\text { Yes }\end{array}$ & 1.84 & $0.9-3.75$ & 0.094 \\
\hline Drink & $\begin{array}{l}\text { No } \\
\text { Yes }\end{array}$ & 1.63 & $0.88-3.02$ & 0.120 \\
\hline Fbg ${ }^{\pi}$ & & 1.35 & $1.01-1.8$ & 0.043 \\
\hline Differentiation & $\begin{array}{l}\text { Well } \\
\text { Poor }\end{array}$ & 2.58 & $1.41-4.72$ & 0.002 \\
\hline Positive nodes & $\begin{array}{l}\text { Negative } \\
\text { Positive }\end{array}$ & 1.84 & $1.03-3.28$ & 0.039 \\
\hline Positive margin & $\begin{array}{l}\text { Negative } \\
\text { Positive }\end{array}$ & 1.57 & $0.86-2.87$ & 0.139 \\
\hline
\end{tabular}

Notes: ${ }^{\dagger} \mathrm{HR}$, hazard ratio; ${ }^{\ddagger} 95 \% \mathrm{Cl}, 95 \%$ confidence interval; ${ }^{\S} \mathrm{P}$ value $<0.05$, significant; " $\mathrm{Fbg}$, fibrinogen. 


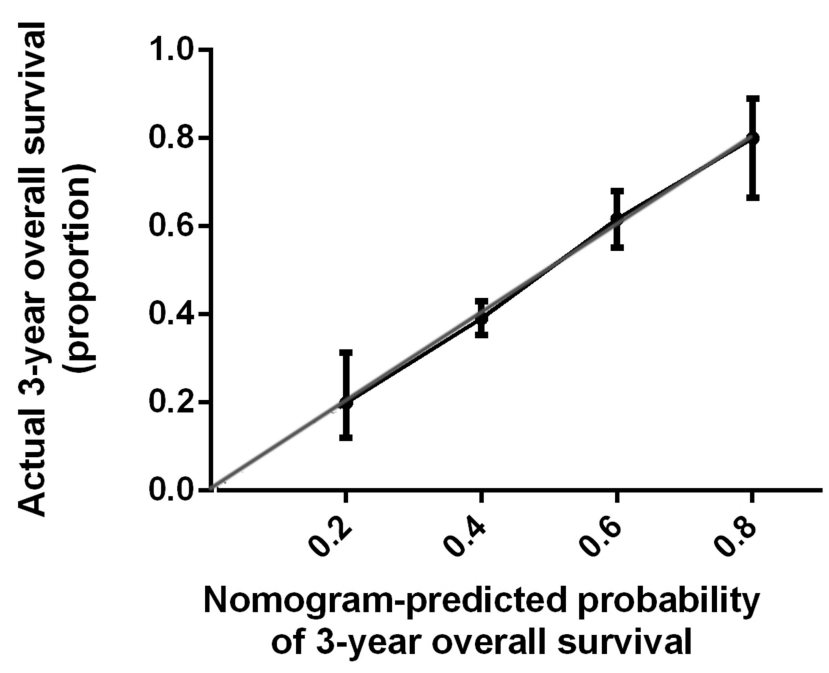

Figure 2 Calibration plot comparing predicted and observed overall survival probabilities after 3 years of follow-up. The nomogram-predicted and observed probabilities of overall survival are plotted on the $x$ - and $y$-axes, respectively. Thin gray line represents the reference.

\section{Discussion}

Here we conducted a study of DCC-related prognosis of patients $(n=147)$ treated at a single center during the past 5 years. Among 10 patients with liver-related tumors, 1 was diagnosed with DCC. ${ }^{15}$ Although several studies identified prognostic factors associated with DCC, few prognostic models are available to systematically evaluate their effects on the survival of patients with DCC. ${ }^{16,17}$ With improvements in surgical techniques and instrumentation, patients suffer fewer surgery-related injuries. Moreover, the maturity of postoperative chemotherapy regimens lengthens overall survival. The effects of treatment outcomes achieved 10 years ago cannot be compared with those today. To develop an accurate prognostic model that reflects current practice, we therefore selected only patients diagnosed with DCC during the past 5 years. We identified several prognostic factors that allowed the development of an efficient nomogram to predict the prognosis of patients with DCC.

The nomogram will serve as a convenient clinical tool. If a patient comes to the outpatient clinic with a query

Table 4 The AUROC of Nomogram (Model I) Compared with AJCC TNM Classification (Model 2)

\begin{tabular}{|l|l|l|l|}
\hline Time & $\begin{array}{l}\text { Nomogram } \\
\text { (Model I) }\end{array}$ & $\begin{array}{l}\text { AJCC TNM } \\
\text { Classification (Model 2) }\end{array}$ & P value \\
\hline Month 12 & 0.724 & 0.562 & $<0.001$ \\
Month24 & 0.758 & 0.638 & $<0.001$ \\
Month36 & 0.782 & 0.599 & $<0.001$ \\
\hline
\end{tabular}

about their prognosis after surgery, physicians should evaluate the variables as follows: jaundice, alcohol consumption, high Fbg, low differentiation, positive lymph nodes, and positive margins. The physician would then use our present nomogram to assign a prognostic score, which likely will answer the patients' questions. For example, prediction of a low survival rate may indicate that patients should undergo more frequent follow-up examinations and potentially more aggressive treatments.

Our prognostic model nomogram achieved higher predictive ability compared with that of the AJCC TNM classification, which is a widely used. The model includes a limited number of tumor-related variables that do not take into account other significant risk factors. Furthermore, the AJCC system lacks flexibility in clinical use as detailed pathologic reports are difficult to obtain before surgery. Nomograms that include multiple factors are available for predicting the prognosis of patients with certain cancers. ${ }^{18}$ However, few nomograms are available for DCC, particularly for application to patients in China. We established a nomogram evaluating a combination of several factors and help clinical physicians to make decision.

Preoperative-related indicators (jaundice, alcohol consumption, high Fbg) were significant predictors of prognosis. Our evaluation system is therefore applicable for evaluating patients before they undergo surgery. Our final model included jaundice, alcohol consumption, high Fbg, low differentiation, positive lymph nodes, and positive margins. Jaundice, a common symptom of DCC, was a significant prognostic factor here. Preoperative relief of jaundice using biliary drainage improves liver function and reduces postoperative complications of patients with cholangiocarcinoma. ${ }^{19}$ Our present study supports intervention using such preoperative management.

Alcohol consumption was associated here with poor prognosis of DCC, which is consistent with other studies. $^{20}$ The activation of the carcinogenic properties of ethanol metabolites may explain this association. ${ }^{21}$ Elevated Fbg was another prognostic factor, which is consistent with findings that elevated levels of D-dimer in cholangiocarcinoma indicate the potential role of tumorassociated coagulopathy ${ }^{22}$. Fibrinogen and D-dimer indicate a hypercoagulable state. Tissue hypoxia induced by a growing tumor combined with procoagulant and angiogenic factors produced by tumor cells, as well as with endothelial cell injury caused by tumor cells, may contribute to the underlying mechanism. ${ }^{23}$ 
A

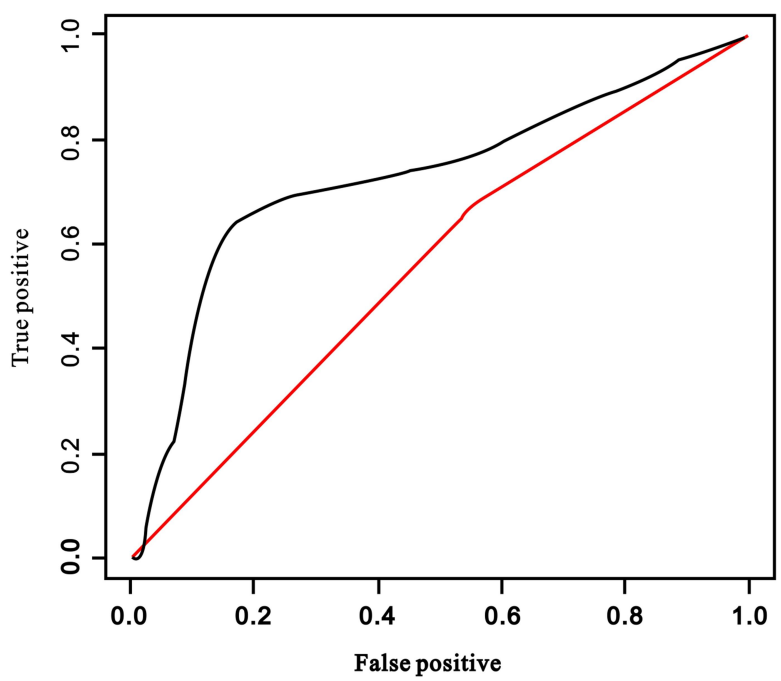

C

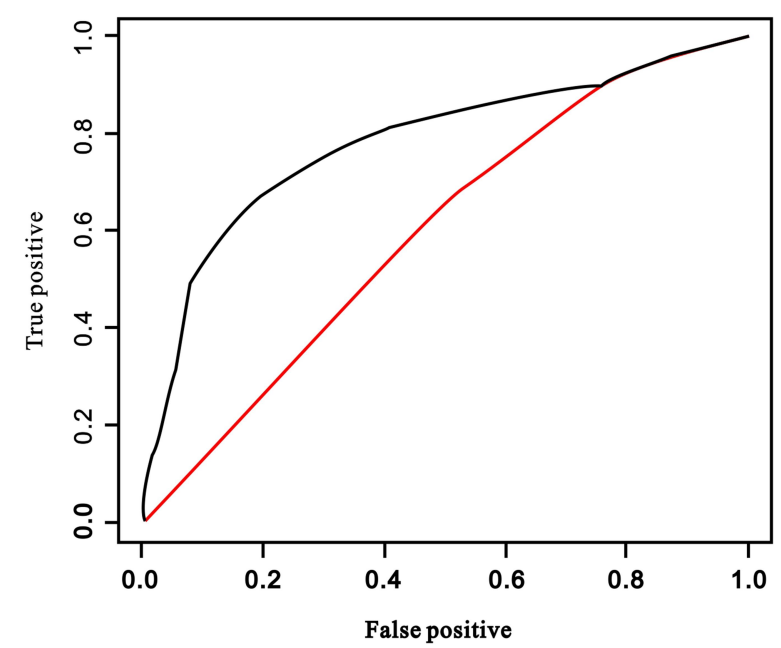

B Model 1 (black) vs Model 2 (Red)

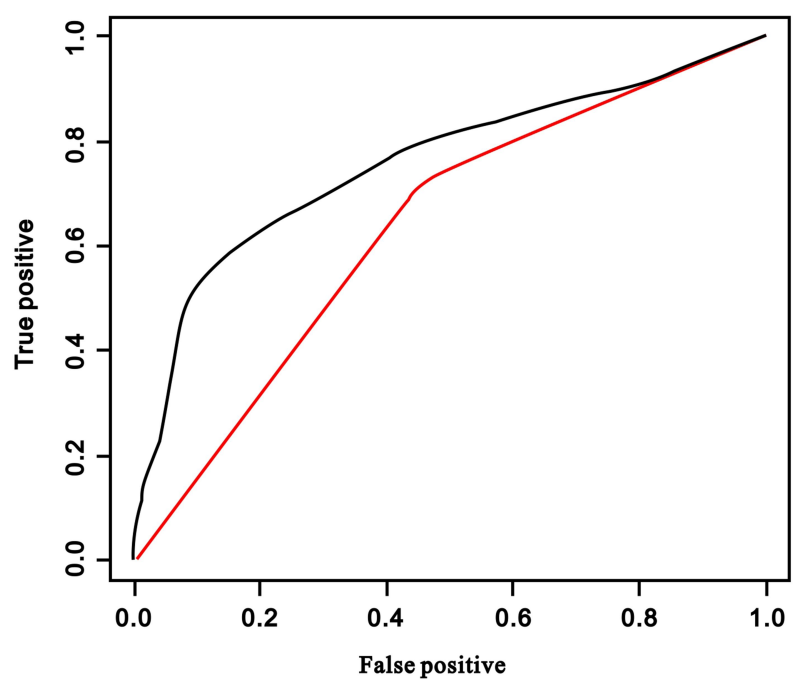

Figure 3 The AUROC of the nomogram compared with the AJCC TNM classification. The two models were compared at the time nodes (A) I year, (B) 2 years, and (C) 3 years. Nomogram (black line) was consistently more accurate than the AJCC TNM classification (red line).

In the present study, lymph node metastasis was significantly associated with shorter overall survival. ${ }^{24}$ The prognostic value of lymph node metastasis may indicate the postoperative growth and dissemination of a tumor after it invades the lymph nodes. ${ }^{25}$ Therefore, our results indicate that lymph node metastasis is associated with worse prognosis, suggesting that surgery, including lymphadenectomy and histopathological analyses of lymph nodes, are important for managing patients with DCC patients. Moreover, lymph node micrometastasis, which may not be detected using routine hematoxylin and eosin staining, may correlate with shorter overall survival of patients with cholangiocarcinoma. ${ }^{24,26}$
We show here that the degree of tumor differentiation was a major factor that influenced prognosis. Poorly differentiated tumor tissues are more invasive and therefore have a higher potential for metastasis; and poorly differentiated cholangiocarcinoma cells are more likely to metastasize. ${ }^{27,28}$ The mechanism involves epithelialmesenchymal transitions within tumors, and the degree of tumor differentiation therefore directly determines the choice of postoperative chemotherapy. ${ }^{5}$

The prognostic significance of a positive margin was demonstrated in the present study. A negative surgical margin is required to effectively treat a carcinoma. However, DCC often shows extensive microscopic spread, and margin- 
negative resection rates range from $46 \%$ to $100 \% .^{9}$ The present study demonstrates the prognostic value of a positive margin, which is consistent with the findings of other studies, reinforcing the importance of achieving tumorfree surgical margins in patients with DCC. ${ }^{29,30}$

Although we performed rigorous validation using bootstrapped calibrations, future externally validation is required. For example, we will conduct analyses of multicenter data to verify the accuracy and usefulness of our model and to increase the validity of the data. Furthermore, exon-sequencing data ${ }^{31}$ combined with clinical factors and molecular genetic analyses will guide the development of targeted therapy.

\section{Conclusion}

We developed a nomogram for predicting the prognoses of patients with distal cholangiocarcinoma who underwent pancreatoduodenectomy at a large oncology center in China. The nomogram was more effective than the AJCC system and therefore will have great clinical value.

\section{Acknowledgments}

We are grateful for the participation of the outpatients, without whom our study would not have been possible.

\section{Author Contributions}

Qiao Chen, Jiayi Li and Shunda Du contributed to research concept and design.

Qiao Chen, Jiayi Li, Bao Jin, Xiangan Wu and Yue Shi contributed to data collection. Qiao Chen and Jiayi Li contributed to data analysis and manuscript writing.

Shunda Du, Haifeng $\mathrm{Xu}$, Yongchang Zheng, Yingyi Wang, Xin Lu, Xinting Sang and Yilei Mao contributed to critical revision of the article.

All authors made a significant contribution to the work reported, whether that is in the conception, study design, execution, acquisition of data, analysis and interpretation, or in all these areas; took part in drafting, revising or critically reviewing the article; gave final approval of the version to be published; have agreed on the journal to which the article has been submitted; and agree to be accountable for all aspects of the work.

All of the authors contributed to final approval of article.

Qiao Chen and Jiayi Li contributed equally to this work and should be considered co-first authors.

\section{Funding}

This research was supported by National Natural Science Foundation of China (No. 81972698) and Chinese Academy of Medical Sciences Initiative for Innovative Medicine (CAMS-2017-I2M-4-002). The funders had no role in study design, data collection and analysis, decision to publish, or preparation of the manuscript.

\section{Disclosure}

The authors report no conflicts of interest for this work.

\section{References}

1. Saha SK, Zhu AX, Fuchs CS, Brooks GA. Forty-year trends in cholangiocarcinoma incidence in the U.S.: intrahepatic disease on the rise. Oncologist. 2016;21(5):594-599. doi:10.1634/theoncologist.2015-0446

2. Gupta A, Dixon E. Epidemiology and risk factors: intrahepatic cholangiocarcinoma. Hepatobiliary Surg Nutr. 2017;6(2):101-104. doi:10.21037/hbsn.2017.01.02

3. Banales JM, Cardinale V, Carpino G, et al. Expert consensus document: cholangiocarcinoma: current knowledge and future perspectives consensus statement from the European Network for the Study of Cholangiocarcinoma (ENS-CCA). Nat Rev Gastroenterol Hepatol. 2016;13(5):261-280. doi:10.1038/nrgastro.2016.51

4. Khan SA, Thomas HC, Davidson BR, Taylor-Robinson SD. Cholangiocarcinoma. Lancet. 2005;366(9493):1303-1314. doi:10.1016/s0140-6736(05)67530-7

5. Rizvi S, Khan SA, Hallemeier CL, Kelley RK, Gores GJ. Cholangiocarcinoma - evolving concepts and therapeutic strategies. Nat Rev Clin Oncol. 2018;15(2):95-111. doi:10.1038/nrclinonc.20 17.157

6. Vogel A, Wege H, Caca K, Nashan B, Neumann U. The diagnosis and treatment of cholangiocarcinoma. Deutsches Aerzteblatt Online. 2014. doi:10.3238/arztebl.2014.0748

7. Alvaro D. The challenge of cholangiocarcinoma diagnosis: the turning point is in extracellular vesicles? Hepatology. 2017;66 (4):1029-1031. doi:10.1002/hep.29314

8. Seika P, Klein F, Pelzer U, Pratschke J, Bahra M, Malinka T. Influence of the body mass index on postoperative outcome and long-term survival after pancreatic resections in patients with underlying malignancy. Hepatobiliary Surg Nutr. 2019;8(3):201-210. doi:10.21037/hbsn.2019.02.05

9. Zhou Y, Liu S, Wu L, Wan T. Survival after surgical resection of distal cholangiocarcinoma: a systematic review and meta-analysis of prognostic factors. Asian J Surg. 2017;40(2):129-138. doi:10.1016/j. asjsur.2015.07.002

10. Bochner BH, Kattan MW, Vora KC. Postoperative nomogram predicting risk of recurrence after radical cystectomy for bladder cancer. J Clin Oncol. 2006;24(24):3967-3972. doi:10.1200/jco.2005.05.3884

11. Sternberg CN. Are nomograms better than currently available stage groupings for bladder cancer? J Clin Oncol. 2006;24(24):3819-3820. doi:10.1200/jco.2006.07.1290

12. Wang Y, Li J, Xia Y, et al. Prognostic nomogram for intrahepatic cholangiocarcinoma after partial hepatectomy. J Clin Oncol. 2013;31 (9):1188-1195. doi:10.1200/jco.2012.41.5984

13. Li L, Ding J, Han J, Wu H. A nomogram prediction of postoperative surgical site infections in patients with perihilar cholangiocarcinoma. Medicine. 2017;96(25):e7198. doi:10.1097/md.0000000000007198

14. Zhang H, Yang T, Wu M, Shen F. Intrahepatic cholangiocarcinoma: epidemiology, risk factors, diagnosis and surgical management. Cancer Lett. 2016;379(2):198-205. doi:10.1016/j.canlet.2015.09.008 
15. Mukkamalla SKR, Naseri HM, Kim BM, Katz SC, Armenio VA. Trends in incidence and factors affecting survival of patients with cholangiocarcinoma in the United States. J Natl Compr Canc Netw. 2018;16(4):370-376. doi:10.6004/jnccn.2017.7056

16. Chang JS, Tsai CR, Chen LT. Medical risk factors associated with cholangiocarcinoma in Taiwan: a population-based case-control study. PLoS One. 2013;8(7):e69981. doi:10.1371/journal.pone.006 9981

17. Tao LY, He XD, Qu Q, et al. Risk factors for intrahepatic and extrahepatic cholangiocarcinoma: a case-control study in China. Liver Int. 2010;30(2):215-221. doi:10.1111/j.1478-3231.2009.0 2149.x

18. Ferrone CR, Kattan MW, Tomlinson JS, Thayer SP, Brennan MF, Warshaw AL. Validation of a postresection pancreatic adenocarcinoma nomogram for disease-specific survival. J Clin Oncol. 2005;23 (30):7529-7535. doi:10.1200/jco.2005.01.8101

19. Tajiri T, Yoshida H, Mamada Y, Taniai N, Yokomuro S, Mizuguchi Y. Diagnosis and initial management of cholangiocarcinoma with obstructive jaundice. World J Gastroenterol. 2008;14 (19):3000-3005. doi:10.3748/wjg.14.3000

20. Ye XH, Huai JP, Ding J, Chen YP, Sun XC. Smoking, alcohol consumption, and the risk of extrahepatic cholangiocarcinoma: a meta-analysis. World J Gastroenterol. 2013;19(46):8780-8788. doi:10.3748/wjg.v19.i46.8780

21. Moerman CJ, Bueno de Mesquita HB, Runia S. Smoking, alcohol consumption and the risk of cancer of the biliary tract; a population-based case-control study in the Netherlands. Eur J Cancer Prev. 1994;3(5):427-436. doi:10.1097/00008469-1994090 00-00007

22. Jang JW, Yeo CD, Kim JD, et al. Trousseau's syndrome in association with cholangiocarcinoma: positive tests for coagulation factors and anticardiolipin antibody. J Korean Med Sci. 2006;21(1):155-159. doi:10.3346/jkms.2006.21.1.155

23. Denko NC, Giaccia AJ. Tumor hypoxia, the physiological link between Trousseau's syndrome (carcinoma-induced coagulopathy) and metastasis. Cancer Res. 2001;61(3):795-798.
24. Li Z, Biswas S, Liang B, et al. Integrin $\beta 6$ serves as an immunohistochemical marker for lymph node metastasis and promotes cell invasiveness in cholangiocarcinoma. Sci Rep. 2016;6:30081. doi:10.1038/srep30081

25. Michalopoulos GK. Liver regeneration after partial hepatectomy: critical analysis of mechanistic dilemmas. Am J Pathol. 2010;176 (1):2-13. doi:10.2353/ajpath.2010.090675

26. Mantel HT, Wiggers JK, Verheij J, et al. Lymph node micrometastases are associated with worse survival in patients with otherwise node-negative hilar cholangiocarcinoma. Ann Surg Oncol. 2015;22(Suppl 3):S1107-S1115. doi:10.1245/s10434015-4723-9

27. Ryu HS, Chung JH, Lee K, et al. Overexpression of epithelial-mesenchymal transition-related markers according to cell dedifferentiation: clinical implications as an independent predictor of poor prognosis in cholangiocarcinoma. Hum Pathol. 2012;43(12):2360-2370. doi:10.1016/j. humpath.2012.07.004

28. Navaneethan U, Lourdusamy V, Gk Venkatesh P, Willard B, Sanaka MR, Parsi MA. Bile proteomics for differentiation of malignant from benign biliary strictures: a pilot study. Gastroenterol Rep. 2015;3(2):136-143. doi:10.1093/gastro/gou066

29. Sasaki R, Takeda Y, Funato O, et al. Significance of ductal margin status in patients undergoing surgical resection for extrahepatic cholangiocarcinoma. World J Surg. 2007;31(9):1788-1796. doi:10.1007/s00268-007-9102-7

30. Chua TC, Mittal A, Arena J, Sheen A, Gill AJ, Samra JS. Resection margin influences survival after pancreatoduodenectomy for distal cholangiocarcinoma. Am J Surg. 2017;213(6):1072-1076. doi:10.1016/j.amjsurg.2016.09.049

31. Jiao Y, Pawlik TM, Anders RA, et al. Exome sequencing identifies frequent inactivating mutations in BAP1, ARID1A and PBRM1 in intrahepatic cholangiocarcinomas. Nat Genet. 2013;45 (12):1470-1473. doi:10.1038/ng.2813

\section{Publish your work in this journal}

Cancer Management and Research is an international, peer-reviewed open access journal focusing on cancer research and the optimal use of preventative and integrated treatment interventions to achieve improved outcomes, enhanced survival and quality of life for the cancer patient.
The manuscript management system is completely online and includes a very quick and fair peer-review system, which is all easy to use. Visit http://www.dovepress.com/testimonials.php to read real quotes from published authors. 